\title{
Time to Keratometric Stability After Pterygium Excision and the Associated Factors: A Clinical Perspective
}

This article was published in the following Dove Press journal: Clinical Ophthalmology

\author{
Duangratn Niruthisard' \\ Wasee Tulvatana (iD) \\ Vannarut Satitpitakul ${ }^{2}$ \\ 'Department of Ophthalmology, Faculty of \\ Medicine, Chulalongkorn University and \\ King Chulalongkorn Memorial Hospital, \\ Thai Red Cross Society, Bangkok, Thailand; \\ ${ }^{2}$ Center of Excellence for Cornea and Stem \\ Cell Transplantation, Department of \\ Ophthalmology, Faculty of Medicine, \\ Chulalongkorn University and King \\ Chulalongkorn Memorial Hospital, Thai \\ Red Cross Society, Bangkok, Thailand
}

Correspondence: Vannarut Satitpitakul Center of Excellence for Cornea and Stem Cell Transplantation, Department of Ophthalmology, Faculty of Medicine, Chulalongkorn University and King Chulalongkorn Memorial Hospital, Thai Red Cross Society, 1873 Rama 4 Road, Pathumwan, Bangkok, 10330, Thailand Tel +66894959022

Email Vannarut.s@chula.ac.th
Purpose: To determine the percentage of eyes with corneal astigmatic power stability and mean corneal keratometric power at 6-month post-pterygium excision, and to identify the time, and the associated factors, required to achieve stability.

Methods: This prospective observational study enrolled patients undergoing pterygium excision. Patients were evaluated for baseline characteristics and keratometric data before and every month after pterygium excision for six months using IOL Master $500^{\circledR}$ (Carl Zeiss, Meditec). Clinically stable corneal astigmatic power and keratometric power were, respectively, defined as changes in these parameters of less than 0.25 and 0.27 diopters after two consecutive visits. Time to corneal astigmatic and keratometric power stability, as well as factors associated with the stability, were analyzed.

Results: Forty percent and $73.3 \%$ of eyes, respectively, demonstrated corneal astigmatic and corneal keratometric stability at six months post-operation. Within three months of reaching initial stability, the corneal astigmatic power and the mean keratometric power showed instability in $46.7 \%$ and $27.3 \%$ of patients, respectively. No patients with keratometric stability for more than three months became unstable during the study period. The extension of pterygium exceeding $3.0 \mathrm{~mm}$ was associated with a delay in time to corneal astigmatic stability (HRadjusted $0.41 ; 95 \%$ CI $0.19-0.89 ; \mathrm{P}=0.02$ ).

Conclusion: According to the clinical relevance, $40 \%$ and $73 \%$ of patients, respectively, presented corneal astigmatic and keratometric stability within six months post-operation. Patients with a pterygium extension of more than $3 \mathrm{~mm}$ required a longer time for corneal astigmatic stability. It is recommended that keratometric stability be achieved for at least three months before commencing with additional procedures.

Keywords: pterygium, corneal curvature, keratometry, astigmatism

\section{Introduction}

Pterygium is a benign proliferative fibrovascular conjunctival lesion extending onto the cornea that may result in a significant change to the corneal curvature. ${ }^{1}$ The advancing head of pterygia towards the center of the cornea induces corneal astigmatism by mechanically flattening and distorting the cornea in the axis of pterygium traction. ${ }^{2-4}$ After pterygium excision, the corneal keratometry was observed as unstable for a period of time. Previous studies demonstrated that corneal curvature increased while corneal astigmatism decreased after pterygium surgery. ${ }^{5-9}$

The clinical stability of keratometric parameters is essential in patients requiring consecutive procedures, such as cataract surgery, after pterygium excision. Even 
though many studies showed that there was no statistically significant change of keratometric parameters one to three months after pterygium excision, ${ }^{5-11}$ the keratometric change concerning with clinically significance is still unclear.

In this study, we evaluated the time to stability for corneal astigmatic power and mean keratometric power after pterygium excision, and determined the factors associated with the time to stability.

\section{Materials and Methods}

This study was approved by the Institutional Review Board, Faculty of Medicine, Chulalongkorn University, and followed the tenets of the Declaration of Helsinki. The research protocol was registered in Thai Clinical Trials Registry (TCTR20141012001). Patients undergoing pterygium excision at the outpatient clinic, Department of Ophthalmology, King Chulalongkorn Memorial Hospital, Bangkok, Thailand, were consecutively invited to participate. Written informed consent for the purpose of the study, participation in the study and consequent utilization of clinical data was obtained from each patient.

The sample size was calculated to estimate a proportion with a specific level of confidence and precision using the formula: $n=Z_{\alpha / 2}{ }^{2} \times P \times(1=P) / d^{2}$. Where the alpha level, the expected proportion of corneal astigmatic stability (P), the relative acceptable error (d) and the estimated drop-out were $0.05,0.8,10 \%$ and $20 \%$, respectively, this provided a sample size of 75 .

The study enrolled patients with either primary or recurrent pterygium. We excluded patients that their keratometric data could not be obtained from both non-contact partial coherence interferometry (IOL Master $500^{\circledR}$, Carl Zeiss, Meditec, Jena, Germany) and slit-scanning corneal topography (Orbscan II, Bausch \& Lomb, Rochester, NY, USA). Patients with a history of penetrating or perforating eye injury, precedent ocular surgeries other than pterygium surgery, corneal scarring, or any other corneal diseases were also excluded.

Baseline characteristics including gender, age, laterality of pterygium were recorded preoperatively. Pterygia were graded into atrophic, intermediate, or fleshy types according to Tan et al. ${ }^{12}$ Size of pterygia was measured with a caliper under a surgical microscope. The longest extension of pterygia from the limbus to the apex was recorded in millimeters. In the case of double-head pterygia, an average of the longest extension of pterygia from the nasal and temporal sides was recorded. Keratometric data were collected from all patients before pterygium surgery, and monthly after surgery for 6 months using the IOL Master $500^{\circledR}$. In the case the IOL Master $500^{\circledR}$ could not provide keratometric data, the data were obtained from the Orbscan II. Each measurement was repeated at least 3 times until the discrepancy of keratometric data was less than 0.25 diopters (D). The corneal cylinder and the average of minimum and maximum keratometric powers from the most accurate three measurements were recorded.

Pterygium excision was performed under topical anesthesia by either supervised ophthalmology residents or ophthalmologists. Lidocaine hydrochloride $2 \%$ with Adrenaline 1:80,000 (M\&H Manufacturing Co., Ltd, Samut Prakan, Thailand) was injected subconjunctivally. The head of pterygium was removed with the use of a number 15 surgical scalpel blade. The body of pterygium was then dissected and removed. The bare sclera technique was performed in case of atrophic pterygia. Amniotic membrane or conjunctival membrane graft with sutures were used to cover the exposed sclera in intermediate and fleshy pterygia. After pterygium surgeries, patients were prescribed corticosteroid eye drops for one to three months, antibiotic eye drops until corneal epithelial defect closed and non-preservative artificial tear as needed. All sutures were removed within two weeks of surgery.

The primary outcomes were the percentages of eyes that showed stability of corneal astigmatic power and mean keratometric power six months after pterygium excision, and the time to stability of corneal astigmatic power and mean keratometric power. Corneal astigmatic stability was defined as a period of two consecutive months in which the corneal astigmatic power changed less than $0.25 \mathrm{D}$. The mean keratometric power was an average of maximum and minimum keratometric power at $3 \mathrm{~mm}$ zone. The stability of mean keratometric power was defined as a period of two consecutive months in which the mean keratometric power changed less than 0.27D. The first month of the two consecutive months that these parameters did not exceed the defined criteria was recorded as the time of stability. The secondary outcomes, including the factors associated with the time to stability of each keratometric parameter, were also analyzed.

Survival analysis was used to assess the time to stability of post-operative corneal astigmatic power and mean keratometric power. Univariate and multivariate analyses with the Cox Regression Model were used to evaluate the factors associated with the time to stability of corneal 
astigmatic power and mean keratometric power. Factors which showed P-value less than 0.05 from the univariate analysis were included in the multivariate analysis. Size of pterygium, which was a significant factor considered according to literature reviews $\mathrm{s}^{2,3,5}$ was also included in the multivariate analysis of both corneal astigmatic and mean keratometric stability. P values less than 0.05 were considered statistically significant. The statistical analysis was performed using SPSS Statistics for Windows, Version 17.0. Chicago: SPSS Inc. (SPSS Inc. Released 2008).

\section{Results}

The study enrolled one eye from seventy-five patients. The mean patient age was $55.5 \pm 11.4$ years (range 20 to 76 years). Forty $(53.3 \%)$ patients were female. The mean duration from diagnosis to surgery of pterygium was $10.3 \pm 7.8$ years (range 1 to 40 years). The mean corneal extension of pterygium from limbus was $3.62 \pm 1.28 \mathrm{~mm}$ (range 0.3 to $8 \mathrm{~mm}$ ). Baseline characteristics of patients are shown in Table 1. We obtained preoperative keratometric data in seventy-four eyes using the IOL Master $500^{\circledR}$. One eye required the Orbscan II for keratometric measurement. The median preoperative corneal astigmatism was $-1.32 \mathrm{D}$ (IQR 1.3 ; range -8.6 to $-0.22 \mathrm{D}$ ). The mean preoperative keratometric power was $44.17 \pm 1.59 \mathrm{D}$ (range 41.26 to $48.17 \mathrm{D}$ ).

\section{Corneal Astigmatic Stability}

Thirty of seventy-five eyes $(40.0 \%)$ demonstrated corneal astigmatic stability within the post-operative six months period. The time to corneal astigmatic stability is shown in Figure 1. Thirty percent (17 of 55) of patients with with-the-rule astigmatism and $65 \%$ (13 of 20 ) of patients with against-the-rule astigmatism demonstrated corneal astigmatic stability within six months. The eyes that showed corneal astigmatic stability for three consecutive months remained stable during the study period, while $10(33.3 \%)$ and $4(13.3 \%)$ of 30 eyes, respectively, showed corneal astigmatic changes at two and three months after demonstrating initial corneal astigmatic stability.

The factors associated with the time to corneal astigmatic stability are shown in Table 2 . The length of pterygium, absolute preoperative corneal astigmatism and absolute change of corneal astigmatism one month postsurgery were significantly associated with the time to corneal astigmatic stability using univariate analysis.
Table I Baseline Characteristics of Study Participants

\begin{tabular}{|c|c|}
\hline Characteristics & $\begin{array}{l}\text { Number of Eyes (\%) } \\
\qquad(n=75)\end{array}$ \\
\hline \multicolumn{2}{|l|}{ Age (years) } \\
\hline $0-40$ & II (I4.7) \\
\hline $41-60$ & $38(46.7)$ \\
\hline$>60$ & $26(34.6)$ \\
\hline \multicolumn{2}{|l|}{ Laterality } \\
\hline Right & $40(53.5)$ \\
\hline Left & $35(46.7)$ \\
\hline \multicolumn{2}{|l|}{$\begin{array}{l}\text { Grade of pterygium (atrophic/ } \\
\text { intermediate/fleshy) }\end{array}$} \\
\hline One-headed (63 eyes) & I8 (28.5)/34 (54.0)/II (17.5) \\
\hline \multicolumn{2}{|l|}{ Double-headed ( 9 eyes) } \\
\hline Nasal side & $0 / 8(88.9) / I(11.1)$ \\
\hline Temporal side & I (II.I)/7 (77.8)/I (II.I) \\
\hline \multicolumn{2}{|c|}{$\begin{array}{l}\text { Size of pterygium from limbus to head } \\
\text { (7I eyes) }\end{array}$} \\
\hline$\leq 3 \mathrm{~mm}$ & $30(42.3)$ \\
\hline$>3 \mathrm{~mm}$ & $4 \mid(57.7)$ \\
\hline \multicolumn{2}{|l|}{ Best corrected visual acuity } \\
\hline $20 / 20-20 / 40$ & $54(72.0)$ \\
\hline$<20 / 40-20 / 70$ & II (14.7) \\
\hline$<20 / 70-20 / 200$ & $7(9.3)$ \\
\hline$<20 / 200$ & $3(4.0)$ \\
\hline \multicolumn{2}{|l|}{ Type of astigmatism } \\
\hline With-the-rule & $55(73.3)$ \\
\hline Against-the-rule & $20(26.7)$ \\
\hline \multicolumn{2}{|l|}{ Surgical technique } \\
\hline Amniotic membrane graft & $65(86.7)$ \\
\hline Conjunctival graft & $6(8.0)$ \\
\hline Bare sclera & $4(5.3)$ \\
\hline
\end{tabular}

Multivariate analysis with the Cox Regression Model for the time to corneal astigmatic stability showed the overall model was significant $\left(\chi_{\text {LRT }}^{2}=10.528, d f=3, \quad p<0.05\right)$. Examination of the hazard ratio indicated that those with larger pterygium $(>3 \mathrm{~mm}$ ) had a $59 \%$ less chance of achieving corneal astigmatic stability than those with smaller pterygium $(\leq 3 \mathrm{~mm})$ at any given time.

\section{Mean Keratometric Stability}

Fifty-five of 75 eyes (73.3\%) demonstrated mean keratometric stability six months post-operation. The median survival time of mean keratometric stability was three months after surgery. The time to mean keratometric stability is shown in Figure 2. At two and three months after demonstrating initial keratometric stability, 9 (16.63\%) and $6(10.91 \%)$ of 55 eyes, 


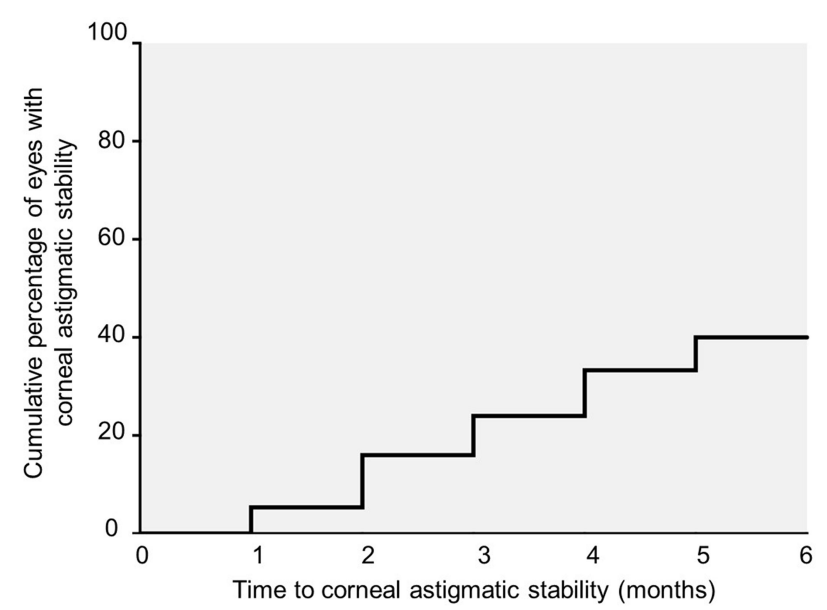

\begin{tabular}{|c|c|c|c|c|c|c|}
\hline $\begin{array}{c}\text { Time after surgery } \\
\text { (months) }\end{array}$ & 1 & 2 & 3 & 4 & 5 & 6 \\
\hline $\begin{array}{c}\text { Cumulative number of } \\
\text { eyes with corneal } \\
\text { astigmatic stability }\end{array}$ & $\begin{array}{c}4 \\
(5.3 \%)\end{array}$ & $\begin{array}{c}12 \\
(16.0 \%)\end{array}$ & $\begin{array}{c}18 \\
(24.0 \%)\end{array}$ & $\begin{array}{c}25 \\
(33.3 \%)\end{array}$ & $\begin{array}{c}30 \\
(40.0 \%)\end{array}$ & $\begin{array}{c}30 \\
(40.0 \%)\end{array}$ \\
\hline
\end{tabular}

Figure I Cumulative percentage of eyes with corneal astigmatic stability after pterygium surgery.

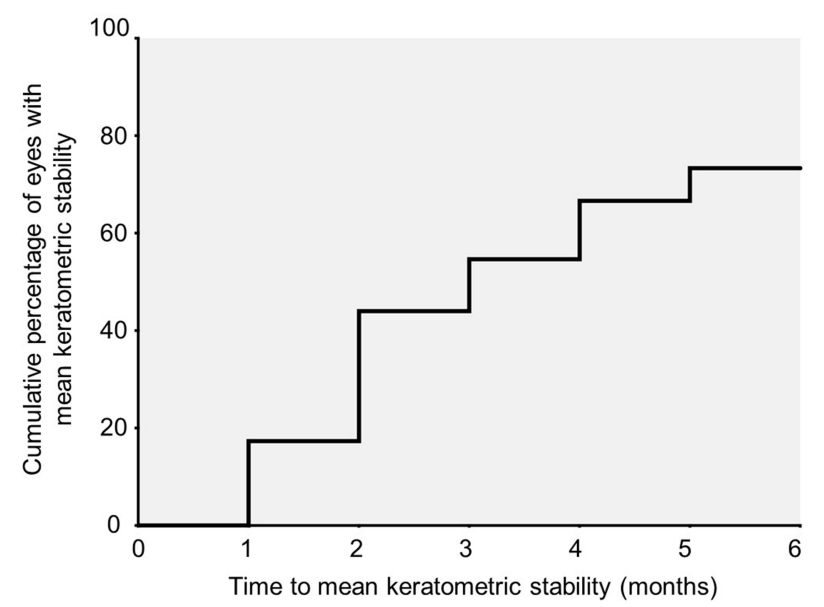

\begin{tabular}{|c|c|c|c|c|c|c|}
\hline $\begin{array}{c}\text { Time after surgery } \\
\text { (months) }\end{array}$ & 1 & 2 & 3 & 4 & 5 & 6 \\
\hline $\begin{array}{c}\text { Cumulative number of } \\
\text { eyes with mean } \\
\text { keratometric stability }\end{array}$ & $\begin{array}{c}13 \\
(17.3 \%)\end{array}$ & $\begin{array}{c}33 \\
(44.0 \%)\end{array}$ & $\begin{array}{c}41 \\
(54.7 \%)\end{array}$ & $\begin{array}{c}50 \\
(66.7 \%)\end{array}$ & $\begin{array}{c}55 \\
(73.3 \%)\end{array}$ & $\begin{array}{c}55 \\
(73.3 \%)\end{array}$ \\
\hline
\end{tabular}

Figure 2 Cumulative percentage of eyes with mean keratometric stability after pterygium surgery.

respectively, showed keratometric change. The eyes that showed keratometric stability for three consecutive months remained stable during the study period.

The factors associated with time to keratometric stability are shown in Table 3 . The duration from diagnosis to surgery of pterygium showed significant association with the time to keratometric stability using univariate analysis. No factor demonstrated an association with the time to keratometric stability in multivariate analysis.

\section{Discussion}

This study evaluated the time to stability of post-operative corneal astigmatism and mean keratometric power after pterygium surgery while taking clinical relevance into account. Only $40 \%$ and $73 \%$ of patients, respectively, demonstrated the stability of corneal astigmatism and keratometric power within the post-operative six months. Moreover, a substantial number of patients showing corneal astigmatic and/or keratometric power stabilities demonstrated changes in these parameters within the three months that followed. In contrast, patients showing keratometric stability for three months demonstrated persistent keratometric stability throughout the study period.

Several previous studies reported corneal astigmatic stability and keratometric stability after pterygium excision by comparing mean astigmatic and keratometric powers between each post-operative visit. These studies revealed no statistically significant change in corneal astigmatism and keratometric power at one to three months post-operation. ${ }^{5-11}$ One recent study by Kam et al demonstrated that post-operative mean keratometry and astigmatism measured by Scheimpflug tomography were stable as soon as 1 week after pterygium excision. ${ }^{13}$ However, the statistical significance shown in the aforementioned studies did not provide the information about the size of keratometric change essential for the clinical application. Before achieving keratometric stability after pterygium surgery, intervention, such as spectacles prescription, intraocular lens measurement or laser keratometric procedure, might result in residual refractive error and an overall poor visual outcome.

In this study, we defined the stability of corneal astigmatism and keratometric power while considering clinical significance. Corneal astigmatic change within $0.25 \mathrm{D}$ does not alter a spectacle power prescription while keratometric power change within $0.27 \mathrm{D}$ does not affect the intraocular lens power selection, commercially available in $0.50 \mathrm{D}$ increments, when calculated using the SRK/T formula. The IOL Master $500^{\circledR}$ is a widely used optical biometer providing good reliability and repeatability data. ${ }^{14,15}$ The IOL Master $500^{\circledR}$ was used as a tool to evaluate the stability of corneal astigmatism and keratometric power because the result would be helpful in a clinical setting, especially in patients undergoing cataract surgery. A recent study also demonstrated that the biometric parameters, including corneal curvature and the repeatability of the IOL Master $500^{\circledR}$ were not significantly different from 
Table 2 Factors Associated with Time to Stability of Corneal Astigmatism After Pterygium Surgery

\begin{tabular}{|c|c|c|c|c|}
\hline Factors & HR $\mathbf{R}_{\text {Crude }}$ & $95 \% \mathrm{Cl}^{\mathrm{a}}$ & HR $\mathbf{R}_{\text {Adjusted }}$ & $95 \% \mathrm{Cl}^{\mathrm{b}}$ \\
\hline \multicolumn{5}{|l|}{ Age (Ref: <40 years) } \\
\hline & \multicolumn{2}{|c|}{$\chi^{2}=0.78, \mathrm{df}=2, \mathrm{P}=0.68$} & & \\
\hline $4 \mathrm{I}-60$ years & 0.75 & $0.28,2.05$ & & \\
\hline$>60$ years & 0.61 & $0.21,1.83$ & & \\
\hline \multicolumn{5}{|l|}{ Grade of pterygium (Ref: grade I: Atrophic) } \\
\hline & \multicolumn{2}{|c|}{$\chi^{2}=1.38, \mathrm{df}=2, \mathrm{P}=0.50$} & & \\
\hline Grade 2: Intermediate & 1.76 & $0.65,4.74$ & & \\
\hline Grade 3: Fleshy & 1.82 & $0.53,6.28$ & & \\
\hline Duration of pterygium (years) & 1.00 & $0.95,1.04$ & & \\
\hline Length of pterygium from the limbus to the apex $(\leq 3,>3 \mathrm{~mm})$ & $0.39^{c}$ & $0.18,0.85$ & $0.4 I^{\mathrm{c}}$ & $0.19,0.89$ \\
\hline Absolute pre-operative corneal astigmatism (diopters) & $0.59^{c}$ & $0.38,0.92$ & 0.69 & $0.39,1.22$ \\
\hline Absolute change of corneal astigmatism one month after surgery (diopters) & $0.52^{c}$ & $0.30,0.93$ & 0.75 & $0.38,1.49$ \\
\hline
\end{tabular}

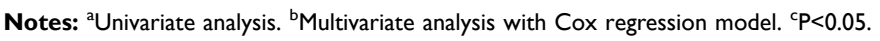

Table 3 Factors Associated with Time to Stability of Mean Keratometric Power After Pterygium Surgery

\begin{tabular}{|c|c|c|c|c|}
\hline Factors & HR $_{\text {Crude }}$ & $95 \% \mathrm{Cl}^{\mathrm{a}}$ & HR $\mathbf{R}_{\text {Adjusted }}$ & $95 \% \mathrm{Cl}^{\mathrm{b}}$ \\
\hline \multicolumn{5}{|l|}{ Age (Ref:<40 years) } \\
\hline & \multicolumn{2}{|c|}{$\chi^{2}=4.14, \mathrm{df}=2, \mathrm{P}=0.13$} & \multicolumn{2}{|c|}{$\chi^{2}=3.90, \mathrm{df}=2, \mathrm{P}=0.14$} \\
\hline $4 I-60$ & 1.30 & $0.57,2.96$ & 1.16 & $0.50,2.68$ \\
\hline$>60$ & 0.70 & $0.29,1.72$ & 0.63 & $0.25,1.55$ \\
\hline \multicolumn{5}{|l|}{ Grade of pterygia (Ref: grade I: Atrophic) } \\
\hline & \multicolumn{2}{|c|}{$\chi^{2}=0.16, \mathrm{df}=2, \mathrm{P}=0.93$} & & \\
\hline Grade 2: Intermediate & 0.88 & $0.47,1.65$ & & \\
\hline Grade 3: Fleshy & 0.92 & $0.40,2.11$ & & \\
\hline Duration of pterygia & $1.03^{c}$ & $1.00,1.06$ & 1.03 & $0.99,1.07$ \\
\hline Length of pterygia from the limbus to the apex $(\leq 3,>3 \mathrm{~mm})$ & 1.05 & $0.60,1.86$ & 0.96 & $0.54,1.70$ \\
\hline Pre-operative mean corneal refraction (diopters) & 1.09 & $0.93,1.28$ & & \\
\hline Absolute change of mean corneal refraction one month after surgery (diopters) & 0.86 & $0.60,1.22$ & & \\
\hline
\end{tabular}

Notes: ${ }^{a}$ Univariate analysis. ${ }^{b}$ Multivariate analysis with Cox regression model. ${ }^{\mathrm{C}} \mathrm{P}<0.05$.

the repeatability of the IOL Master $700^{\circledR}$ and the Pentacam AXL. ${ }^{16}$

Our findings demonstrated that the percentage of patients with stability of keratometric power was higher than the percentage of patients with stability of corneal astigmatic power at six months after pterygium excision.
Moreover, all patients with stability of corneal astigmatic power showed stability of keratometric power. The procedures following pterygium surgery, which require only refractive power stability such as cataract surgery with non-toric intraocular lens implantation, can be performed with lesser time lapsed between procedures, while 
procedures including laser refractive surgery, astigmatic keratotomy, limbal relaxing incision, cataract surgery with toric intraocular lens implantation and spectacle prescription, in which stability of corneal astigmatism is essential for the best outcomes, require a longer followup period.

After showing the stability of corneal astigmatic and/or keratometric power, some patients demonstrated changes in keratometric parameters within three months. However, patients who showed keratometric stability for three consecutive months remained stable throughout the study period. Thus, after reaching keratometric stability, we recommend following up with patients at least three months before proceeding with consecutive refractive procedures. Keratometric change after achieving initial stability, although considered the genuine change, may be due to pre-existing dry eye syndrome or measurement error. To obtain accurate keratometric data, these factors should be considered and properly managed.

Previous studies showed that the size of pterygium had significant positive correlation with corneal astigmatism, total higher order aberration and amount of corneal astigmatic change after pterygium surgery. ${ }^{9,11,17}$ To our knowledge, the factors associated with time to keratometric stability are still unknown. We found that pterygium with corneal extension more than $3 \mathrm{~mm}$ had 59\% less chance of corneal astigmatic stability when compared to pterygium with corneal extension equal or less than $3 \mathrm{~mm}$ at any time point within six months follow-up period.

There were some limitations in our study. First, the number of patients with recurrent and double head pterygium was too small to be separately evaluated. Second, long-term stability of keratometric power and corneal astigmatism beyond six months post-operation remains unknown.

\section{Conclusion}

Within the post-operative six months, $40 \%$ and $73 \%$ of the patients demonstrated clinical stability of corneal astigmatism and keratometric power, respectively. While some patients showed keratometric changes within three months of achieving stability, patients who showed keratometric stability for three consecutive months demonstrated persistent keratometric stability afterward. The time to corneal astigmatic stability was positively associated with the length of pterygium that extended into cornea. This study provides an insight into the keratometric stability after pterygium surgery, which can be used to anticipate the appropriate interval before proceeding with additional procedures, such as refractive surgery, intraocular lens measurement or spectacle prescription.

\section{Acknowledgments}

This study was supported by Ratchapiseksompotch Fund (Faculty of Medicine, Chulalongkorn University, Bangkok, Thailand, grant number RA57/049).

\section{Disclosure}

Ms Duangratn Niruthisard reports grants from Ratchadaphiseksomphot Endowment Fund, during the conduct of the study. The authors report no other potential conflicts of interest in this work.

\section{References}

1. Liu T, Liu Y, Xie L, et al. Progress in the pathogenesis of pterygium. Curr Eye Res. 2013;38(12):1191-1197. doi:10.3109/0271368 3.2013.823212

2. Nejima R, Masuda A, Minami K, et al. Topographic changes after excision surgery of primary pterygia and the effect of pterygium size on topographic restoration. Eye Contact Lens. 2015;41(1):58-63. doi:10.1097/ICL.0000000000000065

3. Tomidokoro A, Oshika T, Amano S, et al. Quantitative analysis of regular and irregular astigmatism induced by pterygium. Cornea. 1999;18(4):412-415. doi:10.1097/00003226-199907000-00004

4. Hansen A, Norn M. Astigmatism and surface phenomena in pterygium. Acta Ophthalmol. 1980;58:174-181. doi:10.1111/j.17553768.1980.tb05706.x

5. Kheirkhah A, Safi H, Nazari R, et al. Effects of pterygium surgery on front and back corneal surfaces and anterior segment parameters. Int Ophthalmol. 2012;32(3):251-257. doi:10.1007/s10792-0129560-2

6. Kheirkhah A, Safi H, Molaei S, et al. Effects of pterygium surgery on front and back corneal astigmatism. Can J Ophthalmol. 2012;47 (5):423-428. doi:10.1016/j.jcjo.2012.07.002

7. Errais K, Bouden J, Mili-Boussen I, et al. Effect of pterygium surgery on corneal topography. Eur J Ophthalmol. 2008;18(2):177-181. doi:10.1177/112067210801800203

8. Ozdemir M, Cinal A. Early and late effects of pterygium surgery on corneal topography. Ophthalmic Surg Lasers Imaging. 2005;36 (6):451-456. doi:10.3928/1542-8877-20051101-04

9. Tomidokoro A, Miyata K, Sakaguchi Y, et al. Effects of pterygium on corneal spherical power and astigmatism. Ophthalmology. 2000;107:1568-1571. doi:10.1016/S0161-6420(00)00219-0

10. Yagmur M, Ozcan AA, Sari S, Ersoz TR. Visual acuity and corneal topographic changes related with pterygium surgery. J Refract Surg. 2005;21(2):166-170. doi:10.3928/1081-597X-20050301-12

11. Bahar I, Loya N, Weinberger D, Avisar R. Effect of pterygium surgery on corneal topography: a prospective study. Cornea. 2004;23(2):113-117. doi:10.1097/00003226-200403000-00002

12. Tan DT, Chee SP, Dear KB, Lim AS. Effect of pterygium morphology on pterygium recurrence in a controlled trial comparing conjunctival autografting with bare sclera excision. Arch Ophthalmol. 1997;115:1235-1240. doi:10.1001/archopht.1997.01100160405001

13. Kam KW, Kuan TA, Belin MW, et al. Long-term stability of keratometry, scheimpflug-derived true net power, and total corneal refractive power after primary pterygium excision. Cornea. 2017;36 (11):1358-1363. doi:10.1097/ICO.0000000000001341 
14. Whang WJ, Byun YS, Joo CK. Comparison of refractive outcomes using five devices for the assessment of preoperative corneal power. Clin Exp Ophthalmol. 2012;40:425-432. doi:10.1111/j.14429071.2012.02777.x

15. Shirayam M, Wang L, Weikert MP, et al. Comparison of corneal powers obtained from 4 different devices. Am $J$ Ophthalmol. 2009;148(4):528-535.e1. doi:10.1016/j.ajo.2009.04.028
16. Shajari M, Cremonese C, Petermann K, et al. Comparison of axial length, corneal curvature, and anterior chamber depth measurements of 2 recently introduced devices to a known biometer. $\mathrm{Am}$ J Ophthalmol. 2017;178:58-64. doi:10.1016/j.ajo.2017.02.027

17. Fong KS, Balakrishnan V, Chee SP, Tan DT. Refractive change following pterygium surgery. CLAO J. 1998;24:115-117.

\section{Publish your work in this journal}

Clinical Ophthalmology is an international, peer-reviewed journal covering all subspecialties within ophthalmology. Key topics include: Optometry; Visual science; Pharmacology and drug therapy in eye diseases; Basic Sciences; Primary and Secondary eye care; Patient Safety and Quality of Care Improvements. This journal is indexed on PubMed

Submit your manuscript here: https://www.dovepress.com/clinical-ophthalmology-journal
Central and CAS, and is the official journal of The Society of Clinical Ophthalmology (SCO). The manuscript management system is completely online and includes a very quick and fair peer-review system, which is all easy to use. Visit http://www.dovepress.com/ testimonials.php to read real quotes from published authors. 